\title{
Information on IMIA
}

\section{International Medical Informatics Association}

\author{
BOARD \\ President \\ Hyeoun-Ae Park, Korea (2015 - 2017) \\ President elect \\ Christoph Lehmann, United States (2015 - 2017) \\ Past President \\ Lincoln de Assis Moura Jr., Brazil (2015 - 2017) \\ Secretary \\ Petter Hurlen, Norway (2015 - 2018) \\ Treasurer \\ Sabine Koch, Sweden (2012 - 2018) \\ Vice Presidents \\ Medlnfo \\ Kaija Saranto, Finland (2015 - 2017) \\ Membership \\ Michio Kimura, Japan (2012 - 2018) \\ Services \\ Christoph Lehmann, United States (2012 - 2016) \\ Special Affairs \\ Monique Jaspers, The Netherlands (2013 - 2016) \\ Working \& Special Interest Groups \\ Tze Yun Leong, Singapore (2013 - 2016) \\ CEO \\ Elaine Huesing, Canada (2015 - 2017)
}

IMIA Web site: www.imia.org

\section{IMIA REGIONS}

APAMI: Asia Pacific Association for Medical Informatics Shashi B. Gogia, India, Vice President

EFMI: European Federation for Medical Informatics Patrick Weber, Switzerlan d (2014-2016), Vice President

HELINA: Pan African Health Informatics Association Ghislain Kovematchoua Tchuitcheu, Germany/Cameroon, Vice President

IMIA-LAC: Health Informatics Association for Latin

America and the Caribbean

Amado Espinosa, Mexico, Vice-President

MEAHI - Middle East Association for Health Informatics

Ramin Moghaddam, Iran, Vice President (tbc)

North American Region

Jeremy Theal, Canada, Vice President

\section{WELCOME TO IMIA!}

\section{General}

The International Medical Informatics Association (IMIA) is the world body for health and biomedical informatics. As an 'association of associations', IMIA acts as a bridging organisation to bring together its constituent organisations and their members. IMIA provides leadership and expertise to the multidisciplinary, health focused community and to policy makers, to enable the transformation of healthcare in accord with the worldwide vision of improving the health of the world population. Inherent in IMIA's role is to bring together, from a global perspective, scientists, researchers, users, vendors, developers, consultants and suppliers in an environment of cooperation and sharing.

IMIA was established as an independent, not for profit organisation under Swiss law in 1989. IMIA was originally founded in 1967 as Technical Committee 4 of the International Federation for Information Processing (IFIP). Since 1979, IMIA has evolved from a Special Interest Group of IFIP to its current status as a fully independent international organisation. It continues to maintain its relationship with IFIP as an affiliate organisation and has an appointed Liaison Officer.

IMIA also has close and collaborative ties with the World Health Organization (WHO) as a NGO (Non Government Organization) in officail relations, with appointed Liaison Officers from both the WHO and IMIA. IMIA is also a Liaison A category organisation in cooperation with the International Organization for Standardization (ISO).

The working language of IMIA is English.

\section{Vision}

The IMIA vision is that there will be a worldwide systems approach for healthcare. Clinicians, researchers, patients and people in general will be supported by informatics tools, processes and behaviours that make it easy to do the right thing, in the right way, at the right time to improve health care for all. This systems approach will incorporate and integrate research, clinical care and public health. To achieve this vision it will require everyone being supported by informatics-based information and communication systems and technologies. This vision is described in the IMIA Strategic Plan. IMIA will fulfil its vision by:

- Being the scientific informatics association through which the world's knowledge leaders come together to effectively and efficiently create, assemble, integrate, synthesize or assimilate intellectual knowledge that is required worldwide to advance biomedical informatics in its role of improving health and healthcare.

- Being the informatics association that effectively and efficiently connects people and the nations of the world to be able to accomplish the above purpose.

\section{Membership}

IMIA membership consists of Member Societies, Institutional and Affiliate Members, Honorary Fellows and Corresponding Members.

Member Societies are generally societies with individual membership, or similar appropriate bodies, which are representative of the biomedical and health informatics activities within a country. In general, only one Member Society is admitted from a country, although in special circumstances, and as approved by the IMIA General Assembly, a country may have more than one Member Society in IMIA. In the absence of a Member Society, IMIA accommodates involvement by individuals through "Corresponding" membership, in particular for developing countries as a means of providing encouragement and support to form a representative Member Society. Information about Member Societies is on the IMIA website, and IMIA assists in promoting the activities and events of its members through the IMIA News site and other channels.

IMIA Member Societies may organise into regional groups. IMIA regions now exist for all parts of the world, i.e. Asia/Pacific 
(APAMI), Europe (EFMI), Latin America and the Caribbean (IMIA-LAC), Africa (HELINA), the Middle East (MEAHI) and North America. Regions are represented at the IMIA General Assembly and Board by Vice Presidents appointed by their respective regional organisations.

Institutional Members include academic institutions, corporations, and other bodies. Corporate members can include vendors, consulting, and technology firms, publishers and other professional organisations. Academic members include universities, medical centres, research centres and other similar institutions. IMIA encourages academic members to meet on an annual basis in conjunction with the IMIA General Assembly, to heighten connectivity and deal with areas of mutual interest.

Affiliate Members consist of international organisations that share an interest in the broad field of health and biomedical informatics. In addition to the WHO and IFIP, the International Federation of Health Information Management Associations (IFHIMA) is an affiliate member of IMIA. IMIA has Liaison Officers to WHO, to IFIP, and to ISO, who are working collaboratively on activities and projects of mutual interest.

Honorary Fellows are individuals who have demonstrated exceptional meritorious service in furthering the aims and interests of IMIA; fellowship is conferred for life.

Working and Special Interest Groups provide opportunities for collaboration among individuals who share common interests in a particular focal field. IMIA currently has two Special Interest Groups (Nursing Informatics and the Francophone SIG). Many of IMIA's 25 active Working and Special Interest Groups hold working conferences on leading edge and timely health, medical and biomedical informatics issues.

\section{Governance}

IMIA is governed by a General Assembly, which meets annually. It consists of one representative from each IMIA Member Society and Institutional Member, Honorary Fellows, chairs of IMIA's Working Groups and SIGs, and representatives from Affiliate Members (the WHO, IFIP, IFHIMA), and each of IMIA's Regions. Only IMIA Member Societies have full voting rights.

The Board of IMIA, elected by the General Assembly, conducts the association's affairs. The day-to-day operations are supported by IMIA's CEO and other staff, who are also responsible for IMIA's electronic services.

The officers of the Board and IMIA's Vice Presidents vigorously pursue IMIA's mission to:

- Monitor the range of special interest areas and focus support on new developments.

- Capitalize on the synergies and collective resources of IMIA's constituents.

- Minimize fragmentation between scientific and professional medical informaticians.

- Ensure successful adaptation to changes in the medical informatics marketplace and discipline.

- Raise the profile and awareness of IMIA within and outside of the IMIA organisation.

- Encourage cooperation between the scientif ic and commercial health informatics communities.

- Equitably balance support to emerging and existing IMIA members.

- Establish and maintain cooperation and harmony with organizations that emerge to address medical informatics issues.

- Continue to position IMIA as the facilitator of medical informatics issues in the international community.

\section{Medlnfo and NI Congress}

IMIA organises the internationally acclaimed "World Congress on Medical and Health Informatics", MedInfo. MedInfo 2015 was held in Sao Paulo, Brazil, and was hosted by the Brazilian Health Informatics Association (Sociedade Brasileira de Informática em Saúde - SBIS), and marked the first time MedInfo was held in Latin America. 2015 was also the start of IMIA's new cycle of MedInfo's being held every two years, previously they were held every three years.

Previous MedInfo events have been held in Stockholm, Sweden (1974), Toronto, Canada, (1977), Tokyo, Japan (1980), Amsterdam, The Netherlands (1983), Washington, USA (1986), Beijing/ Singapore (1989), Geneva, Switzerland (1992), Van- couver, Canada (1995), Seoul, Korea (1998), London, UK (2001), San Francisco, USA (2004), Brisbane, Australia (2007), Cape Town, South Africa (2010) and Copenhagen, Denmark (2013).

MedInfo 2017 will be held in Xiamen, China and hosted by the China Medical Informatics Association (CMIA) from August 21-25, 2017. In 2019, MedInfo will be held in Lyon, France and will be hosted by the French Medical Informatics Association (Association Française d'Informatique Médicale (AIM).

The NI (nursing informatics) Congress has been held since 1982, under the auspices of the IMIA Special Interest Group in Nursing Informatics (IMIA NI SIG). The first NI Congress was held in London, UK, followed by Calgary, Canada (1985), Dublin, Ireland (1988), Melbourne, Australia (1991), San Antonio, Texas, USA (1994), Stockholm, Sweden (1997), Auckland, New Zealand (2000), Rio de Janeiro, Brazil (2003), Seoul, Korea (2006), Helsinki, Finland (2009), Montreal, Canada (2012) and Taipei, Taiwan (2014) . 2014 also marked the start of IMIA's $\mathrm{NI}$ congress being held every two years, rather than every three. NI2016 will be held in Geneva, Switzerland from June 25-29, 2016.

\section{IMIA Recommendations on Health and Biomedical Informatics Education}

Health and biomedical informatics education has existed now for more than 40 years, and the demand is still expanding worldwide. It has long been a key part of IMIA's activity, with IMIA's first Working Group being concerned with education. As the international organization devoted to health and biomedical informatics, IMIA developed recommendations on education in health and medical informatics that were first published in 2000 and have been extensively used in the development of programmes of health and biomedical informatics education. Under the leadership of John Mantas, the IMIA recommendations on education were updated and published in 2010 [5]. They are available through the IMIA website, and we welcome their re-publication and translation. The first translation of the updated recommendations is in Chinese and is available through the IMIA website. 


\section{IMIA Code of Ethics}

IMIA adopted the "IMIA Code of Ethics for Health Information Professionals" in 2002. The code has been translated into several languages, and is freely available to the public at IMIA's website. Work is currently being undertaken to change the way it is presented and continually updated.

\section{Official Journals}

Three scientific publications have been accorded the status of "an Official Journal of the International Medical Informatics Association" since 2003: Methods of Information in Medicine and Applied Clinical Informatics (Schattauer Publishers, Stuttgart) and Elsevier Science's International Journal of Medical Informatics.

\section{New Initiatives and Activities}

An important aspect of IMIA is the development and strengthening of our partnerships and synergies, both within IMIA's community, and by reaching out to other organizations, in particular in the fields of standards and global health. IMIA will also leverage the capacity and diversity of our members and of our regions, which represent the true richness of IMIA. IMIA seeks to continually develop appropriate new initiatives.

\section{Communications and Interaction}

IMIA continues to develop its communication with members and others through its website (www.imia.org); this contains profiles of its members, working groups and activities. IMIA is constantly striving to improve the services it provides to its members and the informatics community in general by promoting free interaction among and between its member network and the biomedical and health informatics community at large. IMIA publishes a monthly email newsletter that is distributed to its members and contacts. Through input from the IMIA Social Media Working Group, further modes of interaction with and between IMIA members and the wider global health and biomedical informatics communities are being developed. IMIA has presences on social media sites, including Twitter (@IMIAtweets), Facebook and LinkedIn, and continues to explore new methods of access to information. 